\title{
Effect of food on the pharmacokinetics of omeprazole, pantoprazole and rabeprazole
}

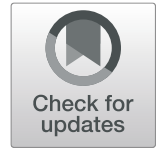

Dolores Ochoa ${ }^{1,2}$, Manuel Román ${ }^{1,2}$, Teresa Cabaleiro ${ }^{1,2}$, Miriam Saiz-Rodríguez ${ }^{1,3}$, Gina Mejía ${ }^{1,2}$ and Francisco Abad-Santos ${ }^{1,2,4^{*}}$ (iD

\begin{abstract}
Background: The pharmacokinetics of proton pump inhibitors (PPIs) may be affected by food intake. We aimed to evaluate the effect of food on the pharmacokinetics of omeprazole, rabeprazole, and pantoprazole.

Setting: The study population comprised 186 healthy volunteers participating in 6 bioequivalence clinical trials.

Method: Subjects were evaluated to determine the effect of a high-fat breakfast on the pharmacokinetics of omeprazole $(n=36)$, rabeprazole $(n=69)$, and pantoprazole $(n=81)$.

Main outcome measure: Drug plasma concentrations were measured using high-performance liquid chromatography coupled to mass spectrometry.

Results: Food affected the pharmacokinetics of omeprazole (increased $T_{\max }$ and decreased AUC and $C_{\text {max }}$ ), pantoprazole (increased $T_{\max }$ and decreased $A \cup C$ ), and rabeprazole (increased $T_{\max } C_{\max }$ and half-life). Food increased variability in $T_{\max }$ for all 3 drugs, delaying absorption around 3 to $4 \mathrm{~h}$ and until $20 \mathrm{~h}$ in some subjects.

Conclusion: As food delays the absorption of PPIs and increases their variability, it would be better to administer these drugs under fasting conditions.

Trial registration: European Union Drug Regulating Authorities Clinical Trials Database: EudraCT: 2004-003863-59 (registration date 05/MAR/2004), EudraCT 2006-001162-17 (registration date 17-MAR-2006), EudraCT: 2007-002489-37 (registration date 12-JUN-2007), EudraCT: 2007-002490-31 (registration date 12-JUN-2007), EudraCT: 2010-024029-19 (registration date 23-NOV-2010).
\end{abstract}

Keywords: Proton pump inhibitors, Food, Pharmacokinetics, Omeprazole, Rabeprazole, Pantoprazole

\footnotetext{
* Correspondence: francisco.abad@salud.madrid.org

${ }^{1}$ Clinical Pharmacology Department, Hospital Universitario de La Princesa,

Instituto Teófilo Hernando, Universidad Autónoma de Madrid (UAM),

Instituto de Investigación Sanitaria La Princesa (IP), C/Diego de León 62,

28006 Madrid, Spain

${ }^{2}$ UICEC Hospital Universitario de La Princesa, Plataforma SCReN (Spanish

Clinical Reseach Network), Instituto de Investigación Sanitaria La Princesa (IP),

Madrid, Spain

Full list of author information is available at the end of the article
}

(C) The Author(s). 2020 Open Access This article is licensed under a Creative Commons Attribution 4.0 International License, which permits use, sharing, adaptation, distribution and reproduction in any medium or format, as long as you give appropriate credit to the original author(s) and the source, provide a link to the Creative Commons licence, and indicate if changes were made. The images or other third party material in this article are included in the article's Creative Commons licence, unless indicated otherwise in a credit line to the material. If material is not included in the article's Creative Commons licence and your intended use is not permitted by statutory regulation or exceeds the permitted use, you will need to obtain permission directly from the copyright holder. To view a copy of this licence, visit http://creativecommons.org/licenses/by/4.0/ The Creative Commons Public Domain Dedication waiver (http://creativecommons.org/publicdomain/zero/1.0/) applies to the data made available in this article, unless otherwise stated in a credit line to the data. 


\section{Bulleted statements on the impact of the research findings on patients, pharmacy or clinical practice}

1. To be more effective, it is recommended to administer PPIs better under fasting conditions.

2. More effective administration could improve patient outcomes.

\section{Background}

Proton pump inhibitors (PPIs) are used for the treatment of acid-related diseases such as gastric and duodenal ulcers, gastroesophageal reflux disease, non-erosive reflux disease, and Zollinger-Ellison syndrome. They are also used in combination with antibiotics for the eradication of Helicobacter pylori [1].

PPIs inhibit gastric $\mathrm{H}^{+} / \mathrm{K}^{+}$-ATPase pump activity, resulting in potent acid inhibition. However, the ability of PPIs to suppress gastric acid varies widely between individuals. Several factors contribute to this phenomenon, including the considerable variation in the oral bioavailability of PPIs, the need for the ATPase pumps to be activated by food, the influence of Helicobacter pylori-associated gastritis, and genetic variation in enzyme activity [2]. Indeed, drug formulation, food intake, and single-nucleotide polymorphisms in cytochrome P450 (CYP) 2C19 enzyme also influence PPIs pharmacokinetic parameters [3-5]. Thus, the time to maximum plasma concentration $\left(\mathrm{T}_{\max }\right)$ varies from $1 \mathrm{~h}$ to $5 \mathrm{~h}$ depending on the drug formulation and/or food effect $[3,4]$.

Tytgat et al. reported that the bioavailability of PPIs was markedly affected by food intake [6]; consequently, PPIs should be taken under fasting conditions. However, PPIs prescribing information is controversial, since some authors state that in case of omeprazole and rabeprazole the concomitant ingestion of food does not affect their bioavailability $[7,8]$, whereas others state that omeprazole should be taken at least $1 \mathrm{~h}$ before a meal [9]. The recommendations for pantoprazole depend on the formulation: tablets could be taken regardless of meal timing, but oral suspension should be taken $30 \mathrm{~min}$ before a meal [10]. To date, there was some evidence that taking PPIs with food affected their absorption. However, until now it has not been rigorously evaluated. This study provides the necessary evidence.

\section{Aim of the study}

This study aimed to evaluate the influence of food on the pharmacokinetic parameters of three PPIs (omeprazole, rabeprazole and pantoprazole) and to determine whether food is more relevant for any of them.

\section{Methods}

\section{Study design}

The study population comprised 186 healthy Caucasian adult volunteers from 6 single-dose bioequivalence clinical trials with pantoprazole $(40 \mathrm{mg}$, enteric-coated tablets), rabeprazole ( $20 \mathrm{mg}$, enteric-coated tablets), and omeprazole (40 mg, oral capsules). The bioequivalence clinical trials were phase I, randomized, open-label, crossover, single-centre, with two periods separated by a 7 -day washout stage. Subjects were randomised to one of the two treatment sequences, RT or TR where R was the reference formulation and $\mathrm{T}$ was the test formulation. Each of the clinical trial was crossover for evaluation of a test formulation compared to a reference formulation either under fed or fasting conditions. Different subjects participated in each trial, but in case of omeprazole, that 35 of 36 volunteers were the same for the trials under fed and fasting conditions. The treatments were allocated in a balanced manner on every inclusion day (blocks of 4 subjects). Our study adheres to CONSORT guidelines.

Considering the expected intrasubject variability for each study, using a multiplicative model, sample size was calculated to reject a difference between both formulations of $20 \%$, with a power of $80 \%$ and an alpha error of 0.05 , according to the bioequivalence approaches habitually accepted by the Health Authorities (acceptance limits of $0.8-1.25$ ).

From those 186 healthy volunteers, 81 subjects received pantoprazole (36 under fasting conditions, EudraCT: 2004-003863-59; and 45 with food, EudraCT 2006-001162-17), 69 received rabeprazole (35 under fasting conditions, EudraCT: 2007-002489-37; and 34 with food, EudraCT: 2007-002490-31) and 36 received omeprazole (35 under fasting conditions and 36 with food; EudraCT: 2010-024029-19). In case of omeprazole, 35 volunteers were the same for both trials. In the trials with food, volunteers fasted for $10 \mathrm{~h}$, the breakfast was taken in $20 \mathrm{~min}$ (between 30 and $10 \mathrm{~min}$ previous to dosing) and the drug was administered $10 \mathrm{~min}$ after the end of breakfast. The meal had a high fat content (50$60 \%$ of total caloric content of the meal) and high calorie count (approximately 800 to $1000 \mathrm{kcal}$ ) according to EMA [11] and FDA [12] guidelines.

The inclusion criteria were as follows: non-smoking male and female volunteers, age 18 to 55 years, body mass index (BMI) within the 18.5-30.0 range, free from any organic or psychiatric conditions, no taking any drug and with normal vital signs, electrocardiogram (ECG), medical records and physical examination. It was not allowed to take other drugs during the study.

\section{Sample processing, quantification, and pharmacokinetic analysis}

Sampling was extended for $12 \mathrm{~h}$ in the clinical trials under fasting conditions and for $24 \mathrm{~h}$ under fed conditions, as follows: (i) Fasting omeprazole - 21 samples: predose, $0.33,0.67,1,1.33,1.67,2,2.33,2.67,3,3.33$, 
$3.67,4,4.5,5,5.5,6,7,8,10$ and $12 \mathrm{~h}$; (ii) fed omeprazole - 26 samples: predose, $0.5,1,1.5,2,2.5,3,3.5,4$, $4.5,5,5.5,6,6.5,7,7.5,8,8.5,9,10,1 \mathrm{~h}, 12,14,17,20$ and $24 \mathrm{~h}$; (iii) fasting pantoprazole - 14 samples: predose, 0.5, 1, 1.5, 2, 2.5, 3, 3.5, 4, 5, 6, 8, 10 and $12 \mathrm{~h}$; (iv) fed pantoprazole - 37 samples: predose, 1, 1.5, 2, 2.5, 3, $3.5,4,4.5,5,5.5,6,6.5,7,7.5,8,8.5,9,9.5,10,10.5,11$, $11.5,12,12.5,13,13.5,14,15,16,17,18,19,20,21,22$ and $24 \mathrm{~h}$; (v) fasting rabeprazole -15 samples: predose, $1,1.5,2,2.5,3,3.5,4,4.5,5,6,7,8,10$ and $12 \mathrm{~h}$; (vi) fed rabeprazole - 37 samples: predose, 1, 1.5, 2, 2.5, 3, 3.5, $4,4.5,5,5.5,6,6.5,7,7.5,8,8.5,9,9.5,10,10.5,11,11.5$, $12,12.5,13,13.5,14,15,16,17,18,19,20,21,22$ and $24 \mathrm{~h}$.

Sample processing, genotyping for CYP2C19 and drug quantification were performed according to Román et al. [5]. As the formulations were bioequivalent, we used the mean concentrations obtained after receiving both test and reference formulations to calculate the pharmacokinetic parameters of each subject. Pharmacokinetic parameters were estimated from the plasma concentration-time data by non-compartmental analysis (WinNonlin Professional, version 2.0., Pharsight Corporation, USA) as reported by Román et al. [5].

\section{Data analysis}

WinNonLin Professional software version 2.0 was used for the statistical analysis. Pharmacokinetic parameters were log-transformed, and AUC and $\mathrm{C}_{\max }$ were adjusted for dose and weight. The values of pharmacokinetic parameters were expressed as mean \pm standard deviation. An analysis of the variance (ANOVA) test was applied to calculate the statistical significance of the differences in pharmacokinetic parameters considering the factors sex and food condition; in the model for omeprazole the factor subject was also included. The $90 \%$ confidence interval of the ratio of geometric means between fed and fast conditions were calculated. To avoid the influence of CYP2C19 polymorphisms, this analysis was repeated in $C Y P 2 C 19 * 1 / * 1$ subjects. $p \leq 0.05$ was considered significant.

\section{Results}

\section{Study population}

We analyzed 186 volunteers (95 men and 91 women). Average age was higher in the omeprazole study (26.73 \pm 5.74 years) than in the pantoprazole study $(23.81 \pm 3.18$ years, $p \leq 0.001)$ and the rabeprazole study $(24.62 \pm 3.78$ years, $p \leq 0.05)$. Weight was similar in the three drugs clinical trials $(66.25 \pm 11.27 \mathrm{~kg}$ for pantoprazole, $68.21 \pm 13.07 \mathrm{~kg}$ for rabeprazole, and $67.69 \pm 12.78$ $\mathrm{kg}$ for omeprazole).

Thirty five subjects from omeprazole study accepted CYP2C19 genotyping, being $16 * 1 / * 1,7 * 1 / * 2,1 * 2 / * 2,10$
$* 1 / * 17$ and $1 * 2 / * 17$. In the case of pantopazole, 33 subjects were genotyped in the fasting trial $(14 * 1 / * 1,6 * 1 / * 2$, $11 * 1 / * 17$ and $2 * 17 * 17)$ and 36 in the fed trial $(14 * 1 / * 1,6$ ${ }^{*} 1 /{ }^{*} 2,14 * 1 / * 17,1 * 17 / * 17$ and $1 * 2 / * 17$ ). In the rabeprazole studies, 30 subjects were genotyped in the fasting trial $\left(14 * 1 /{ }^{*} 1,5 * 1 / * 2,9 * 1 /{ }^{*} 17\right.$ and $\left.2 * 2 / * 17\right)$ and 22 in the fed trial $(9 * 1 / * 1,4 * 1 / * 2,8 * 1 / * 17$ and $1 * 2 / * 17)$.

\section{Role of food in the pharmacokinetics of PPIs}

The effect of food on the pharmacokinetics of omeprazole, pantoprazole, and rabeprazole is shown in Table 1. Mean plasma concentration-time profiles are depicted in Fig. 1.

Under fasting conditions, $\mathrm{T}_{\max }$ was significantly reached earlier for omeprazole $(2 \mathrm{~h})$ than for pantoprazole $(3 \mathrm{~h})$ and rabeprazole $(3.7 \mathrm{~h})(p \leq 0.001)$ (Fig. $2 \mathrm{a})$. In addition, $\mathrm{T}_{\max }$ was also significantly reached earlier for pantoprazole than for rabeprazole $(p \leq 0.001)$.

$\mathrm{T}_{\max }$ was delayed when only pharmacokinetic data after food intake were taken into consideration: $T_{\max }$ for omeprazole $(4.9 \mathrm{~h})$ was earlier than for pantoprazole $(7 \mathrm{~h})$ and rabeprazole $(7.2 \mathrm{~h})(p \leq 0.001)$, but no differences were found between pantoprazole and rabeprazole (Fig. 2a).

The administration of omeprazole with food delayed its mean $\mathrm{T}_{\max }$ by about $3 \mathrm{~h}(p \leq 0.001)$ and increased the variability of $\mathrm{T}_{\max }$, with a range of $1-3.5 \mathrm{~h}$ under fasting conditions and a range of $1-17 \mathrm{~h}$ under fed conditions. Under fed conditions, omeprazole AUC and $C_{\max }$ were 12 and $27 \%$ lower, respectively $(p \leq 0.001)$, and half-life was $15 \%$ higher ( $p \leq 0.05$ and $p \leq 0.001$, respectively).

Food delayed the pantoprazole $\mathrm{T}_{\max }$ by around $4 \mathrm{~h}$ $(p \leq 0.001)$, with a range of $1.5-5 \mathrm{~h}$ under fasting conditions and $1-21 \mathrm{~h}$ under fed conditions. In addition, pantoprazole AUC was 33\% lower $(p \leq 0.001)$ under fed conditions (Fig. 2b).

Food also increased the rabeprazole $\mathrm{T}_{\max }$ by about 3.5 $\mathrm{h}(p \leq 0.001)$, with a range of $2-7 \mathrm{~h}$ under fasting conditions and $3-20 \mathrm{~h}$ under fed conditions. The rabeprazole $\mathrm{C}_{\max }$ and half-life were 21 and $66 \%$ higher under fed conditions ( $p \leq 0.05$ and $p \leq 0.001$, respectively).

When only subjects with CYP $2 C 19 * 1 / * 1$ were taken into account ( $n=82$; 31 omeprazole, 28 pantoprazole, and 23 rabeprazole) similar results were obtained: food increased variability and delayed $\mathrm{T}_{\max }$ by $2.7 \mathrm{~h}$ for pantoprazole (from 3 to $5.7 \mathrm{~h}, p \leq 0.001$ ), $3 \mathrm{~h}$ for omeprazole (from 1.8 to $4.9 \mathrm{~h}, p \leq 0.001$ ), and $5.2 \mathrm{~h}$ for rabeprazole (from $3.9 \mathrm{~h}$ to $9.1 \mathrm{~h}, p \leq 0.001$ ) (Table 2). In addition, under fed conditions, the rabeprazole half-life was higher $(p \leq 0.05)$; and the omeprazole AUC and $C_{\max }$ were lower ( $p \leq 0.05$ and $p \leq 0.01$, respectively).

\section{Role of sex in the pharmacokinetics of PPIs}

There were no differences in the pharmacokinetic parameters between men and women for the three 


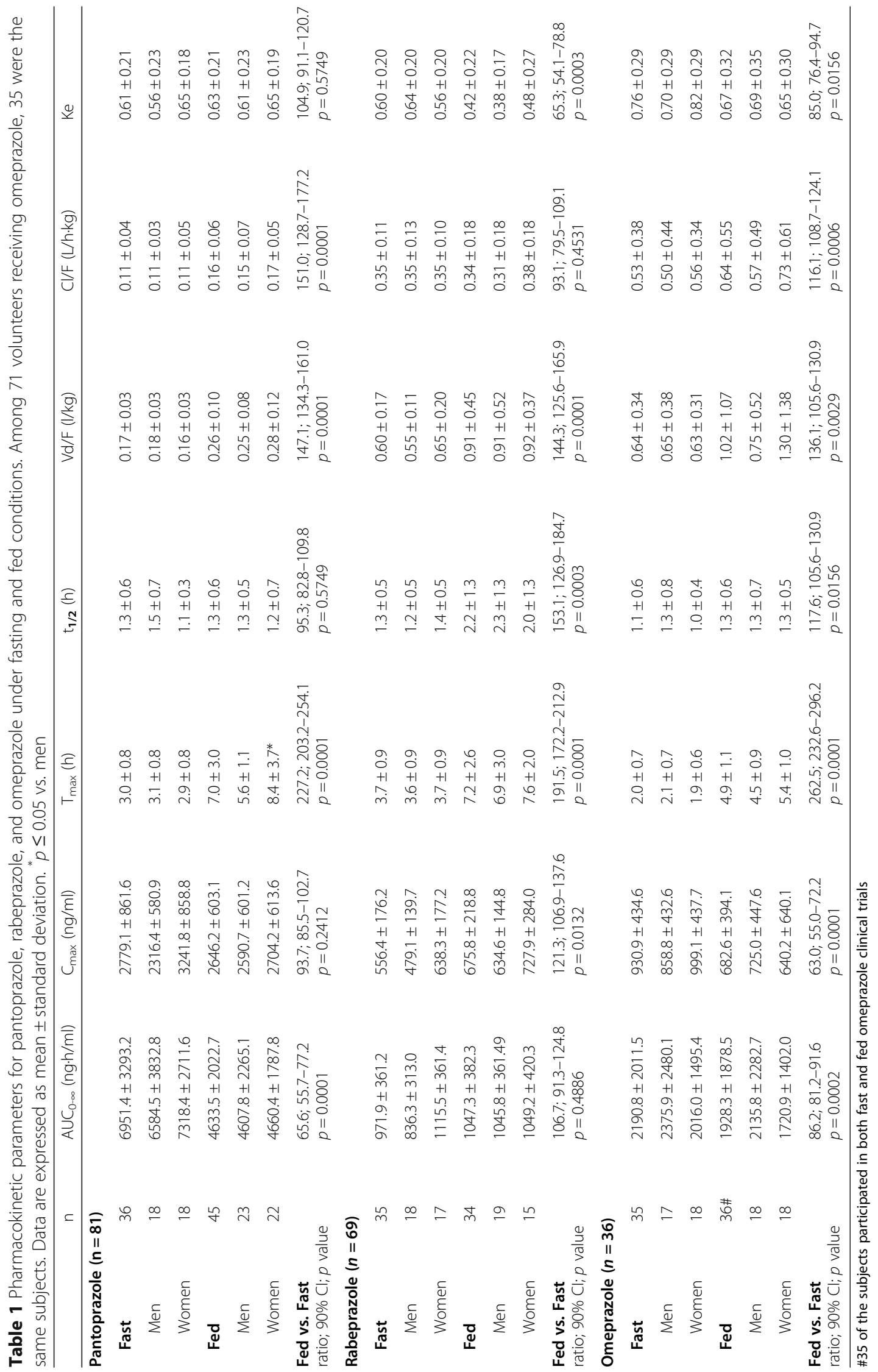


a)

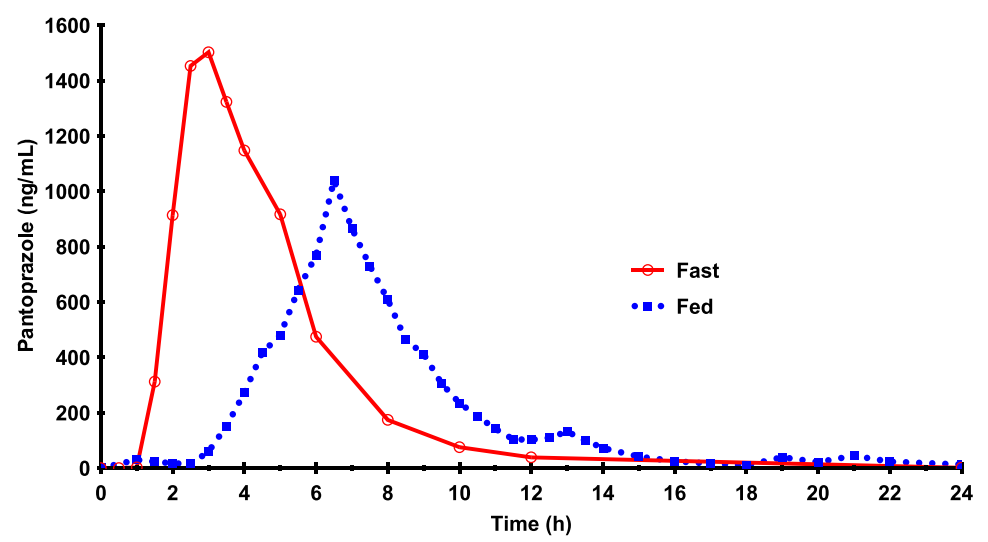

b)

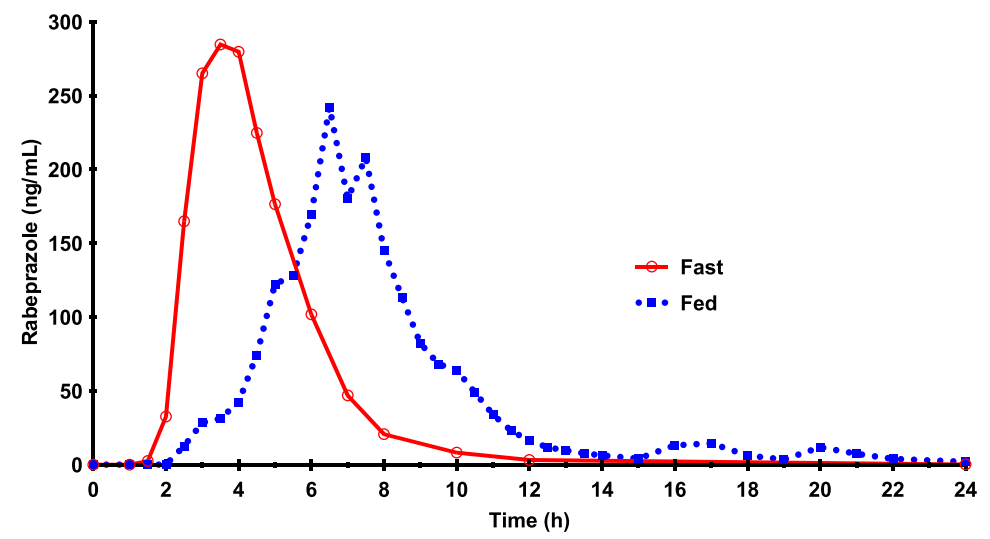

c)

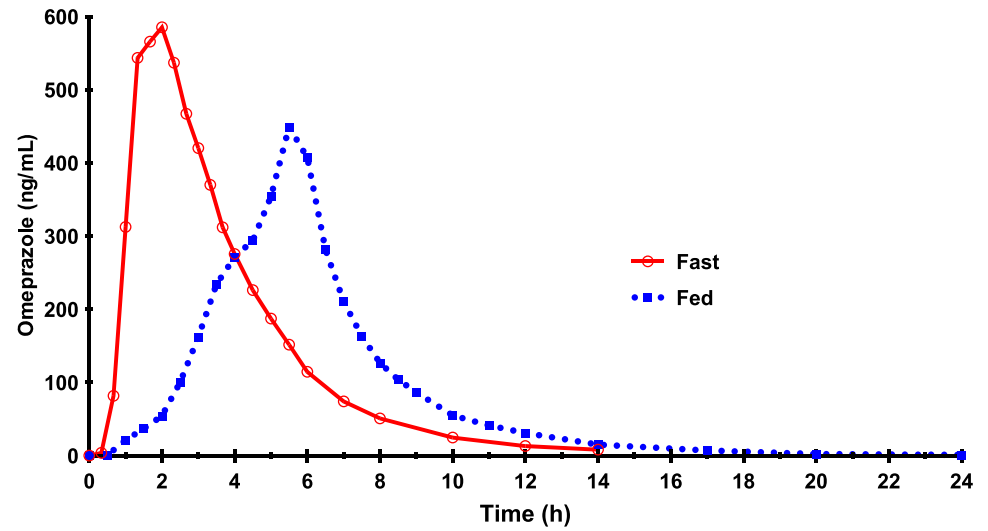

Fig. 1 Mean plasma concentration-time profiles of (a) pantoprazole, (b) rabeprazole and (c) omeprazole, when administered under fed and fasting conditions

drugs, but sex affected the pantoprazole $\mathrm{T}_{\max }$ under fed conditions that was higher in women $(p \leq 0.05)$ (Table 1).

When only CYP2C19*1/*1 subjects are taken into account, under fed conditions rabeprazole AUC was higher $(p \leq 0.05)$ and half-life was lower in women $(p \leq 0.05)$.

\section{Discussion}

Our data showed that food delays the absorption of all PPIs by a mean of $3-4 \mathrm{~h}$. This finding agrees with those of previous studies for esomeprazole [13], tenatoprazole [14], and rabeprazole [15].

The effectiveness of the initial antisecretory action of a PPI depends on factors such as timing in relation to 
a)

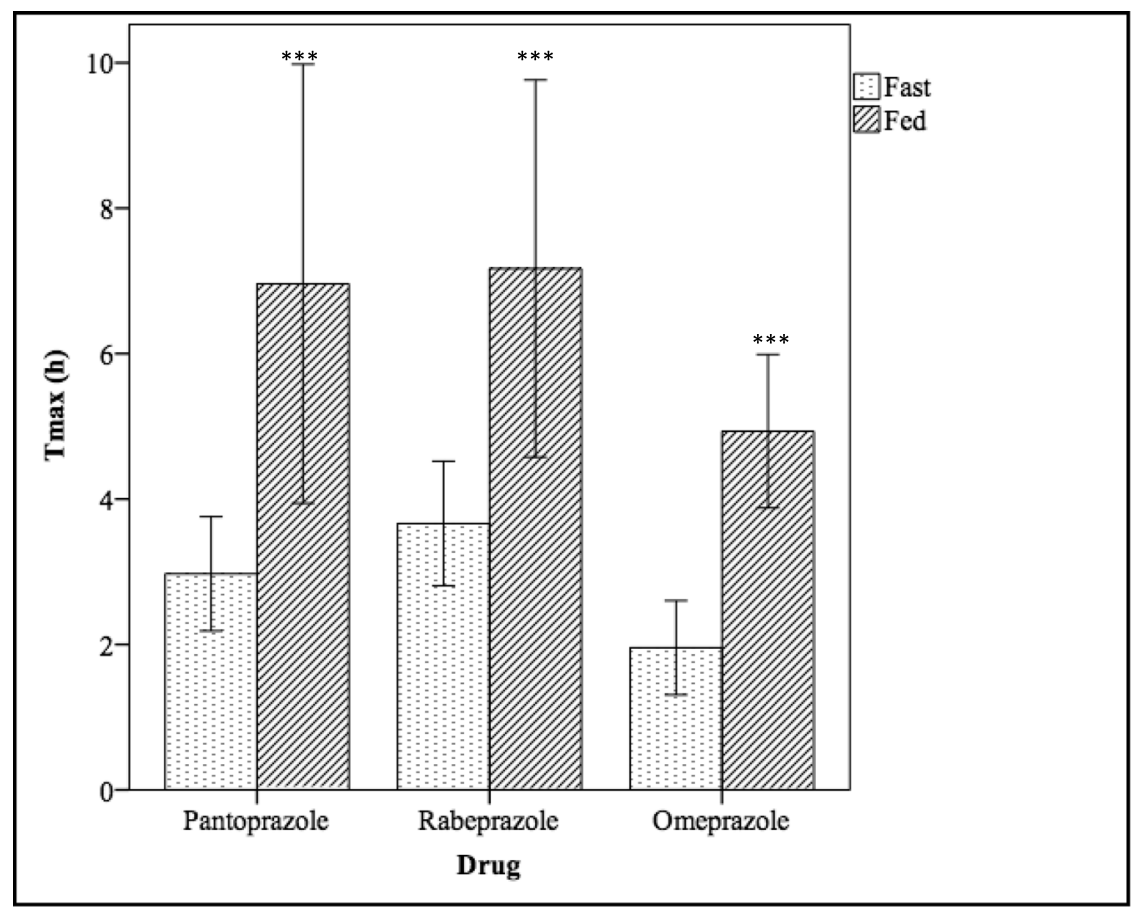

b)

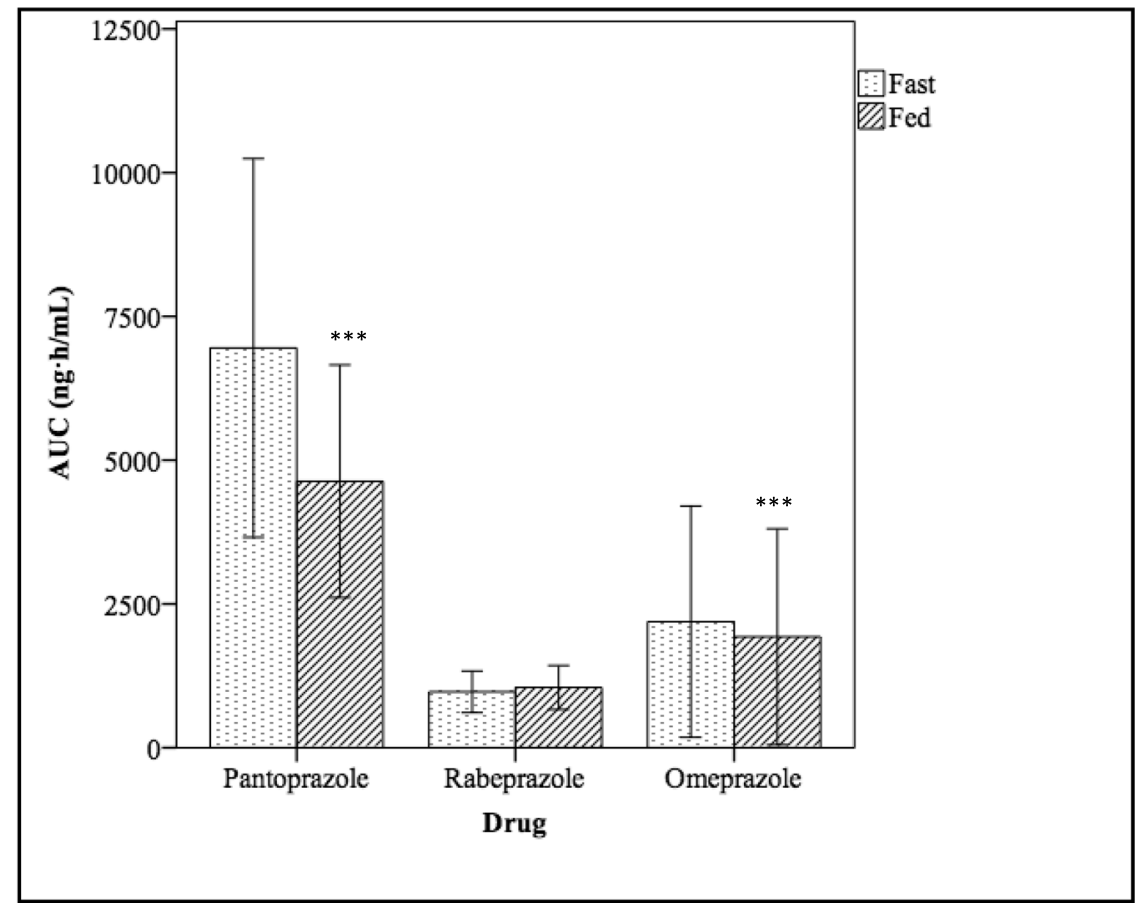

Fig. 2 Differences in PPI Tmax (a) and AUC (b) when administered under fed and fasting conditions. ${ }^{* *} p<0.001$. Bars represented as mean and standard deviation

meals [16]. Because of their short half-lives, PPIs are best administered before a meal or ideally after a period of fasting [17] to ensure that the proton pumps are maximally activated when the drug is available in plasma [16]. Nevertheless, as shown in a study on physician prescription patterns, there is much confusion about the optimal time to take a PPI in relation to meals [17].

AUC is the primary pharmacokinetic parameter to determine the antisecretory effect on omeprazole that is independent on $\mathrm{C}_{\max }$ [18]. Meals with a high fat content 


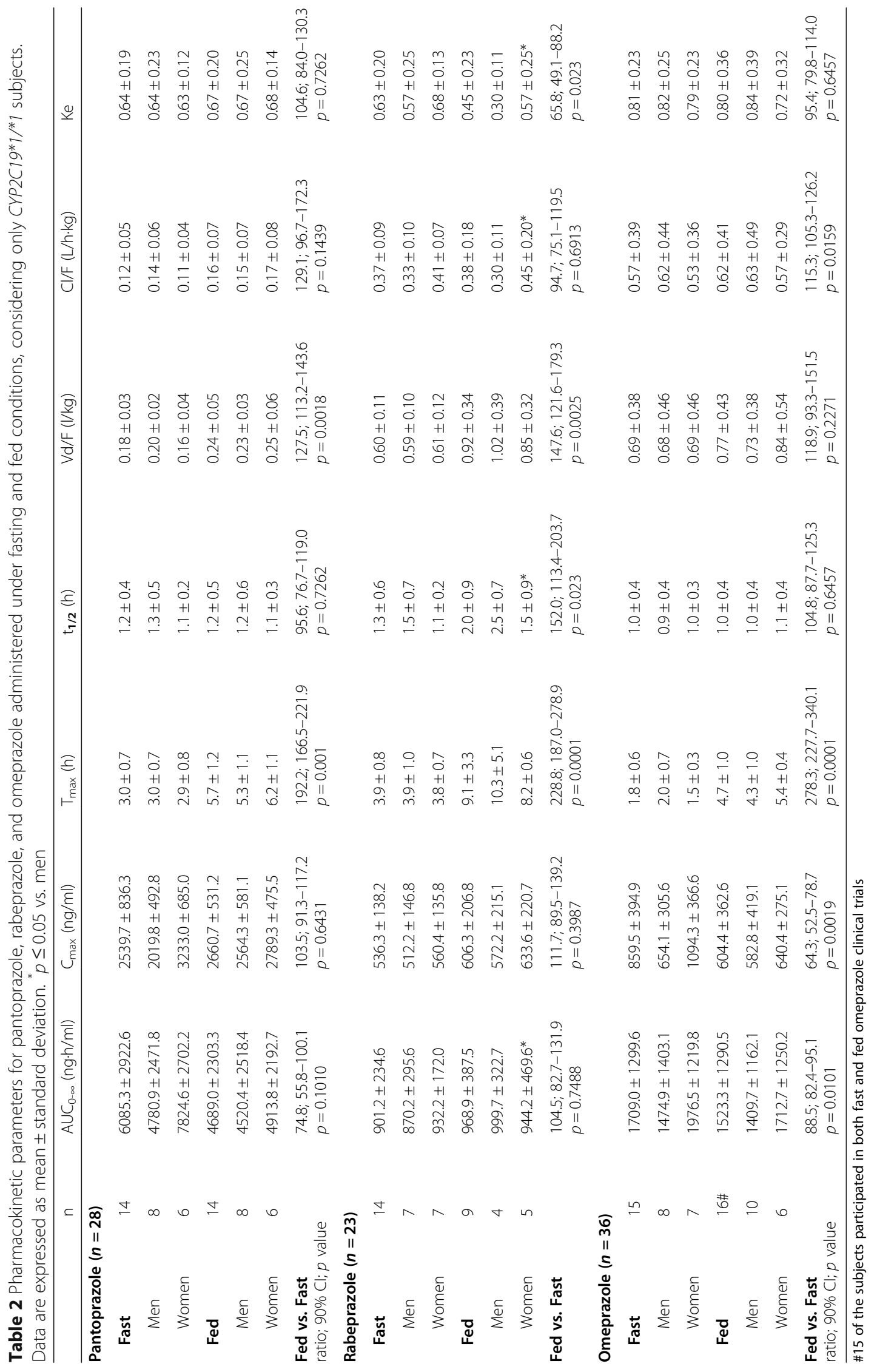


slow gastric emptying [19], thus delaying absorption of the drug and lowering AUC and $C_{\max }$ values [20]. In our opinion, a low-fat breakfast would also influence PPI absorption, however, the effect might be less noticeable and maybe not clinically relevant. In this regard, the presence of food has been reported to reduce the $C_{\max }$ and AUC of omeprazole [21] and esomeprazole [13]. Thomson et al. found that the evening meal reduced the tenatoprazole AUC compared with evening administration of the drug under fasting conditions [14]. Our data are in accordance with this finding, since the pantoprazole AUC and omeprazole AUC and $\mathrm{C}_{\max }$ were significantly lower under fed conditions. A decrease in AUC higher than $20 \%$ may be clinically relevant and can influence the effect on acid secretion. However, it should be further evaluated in chronic PPI treatment, since a single-dose study is not the best approach to established the actual correlation.

However, food increased rabeprazole $\mathrm{C}_{\max }$ and halflife. The metabolism of omeprazole, pantoprazole, and rabeprazole is mediated mainly by CYP2C19 and CYP3A4 [22], but the involvement of CYP3A4 is higher for rabeprazole. The inhibition of CYP3A4 by food may be associate to a lower first-pass metabolism that may explain the increase in $\mathrm{C}_{\max }$ and half-life when rabeprazole is administered under fed conditions. Although the meals given to the volunteers did not contain grapefruit or other known CYP3A4 inhibitors, other components of food could also inhibit in some extent CYP3A4. Moreover, the difference in $\mathrm{C}_{\max }$ can also be due to different genetic profile in subjects participating in the fed and fast studies, since it disappears when considering only CYP2C19*1/*1 subjects (see Table 2 ).

Clearance and volume of distribution cannot be properly calculated when the drug is administered by oral route and we can only calculate these parameters adjusted for bioavailability. In this way, $\mathrm{Cl} / \mathrm{F}$ is calculated as dose/AUC, and $\mathrm{Vd} / \mathrm{F}$ as $\mathrm{Cl} / \mathrm{Ke}$. So, the differences found in these parameters may reflect the differences in bioavailability when the drug is administered with food.

Food increased variability in $\mathrm{T}_{\max }$ for all 3 drugs, delaying absorption around 3 to $4 \mathrm{~h}$ and until $20 \mathrm{~h}$ in some subjects. This can be related with the different effect of a high-fat meal on stomach empting and CYP3A4 inhibition in each subject.

Food intake increases the gastric $\mathrm{pH}$ that activates ATPase molecules, thus resulting in acid secretion [2]. PPIs require secretion of acid for activation and binding to ATPase molecules [13]; therefore, food may affect the pharmacokinetics and pharmacodynamics of PPIs $[3,4]$.

Because of the direct relationship between plasma AUC and the antisecretory effects of PPIs [23, 24], it might be expected that administration of PPIs with food would decrease acid suppression. In this respect,
Andersson et al. reported that inhibition of intragastric acid secretion by esomeprazole increases with higher exposure (AUC) [23]. Therefore, a higher AUC correlates with higher efficacy. For this reason, in the case of pantoprazole and omeprazole, since food decreases the AUC, it would be better to administer these drugs under fasting conditions. However, Iwata et al. observed that pre-dinner administration of PPIs could increase their efficacy in patients with gastroesophageal reflux disease [25].

Since findings are contradictory, some authors state that food did not affect PPIs. In their review, Swan et al. reported that the bioavailability of rabeprazole was not influenced by co-ingestion of food [26]. Junghard et al. found that food decreased AUC and $\mathrm{C}_{\max }$ but had no effect on the percentage of time that intragastric $\mathrm{pH}$ was $>4.0$, because of the more extended plasma concentration profile (longer duration with esomeprazole) [24]. Huber et al. observed that concomitant intake of a standard breakfast with pantoprazole $(40 \mathrm{mg})$ had no effect on bioavailability [27]. In this regard, our study sheds light to this controversy, since we found a clear influence of food intake in omeprazole, rabeprazole and pantoprazole pharmacokinetic parameters.

In our opinion, based on our results, omeprazole and pantoprazole drug label should include the following sentence: "As food delays the absorption of PPIs around 3 to 4 hours and decreases their bioavailability, it would be better to administer these drugs under fasting conditions."

Finally, the effect of sex was analysed because all factors that may influence pharmacokinetics must be taken into account. However, the differences found in AUC for rabeprazole are very small (around 5\%), so it is not expected to be related to a different clinical effect.

\section{Conclusion}

In conclusion, administration of PPIs with food delays absorption around 3 to $4 \mathrm{~h}$ and increases their variability. Food also decreases oral exposure of omeprazole and pantoprazole. Consequently, it would be better to administer PPIs under fasting conditions to improve their efficacy.

\section{Abbreviations \\ AUC: Area under the concentration-time curve; BMI: Body Mass Index; Cmax: Maximum concentration; CYP: Cytochrome P450; \\ ECG: Electrocardiogram; EMA: European Medicines Agency; FDA: US Food and Drug Administration; PPI: Proton pump inhibitor; Tmax: Time to reach the maximum concentration}

\section{Acknowledgements}

This study would not have been possible without the cooperation of the volunteers. We are grateful to Mr. Thomas O'Boyle for writing assistance, which was financed by Fundación de Investigación Biomédica del Hospital Universitario de La Princesa. 


\section{Authors' contributions}

D.O., M.S.R. and T.C. wrote the manuscript; D.O., M. R. and F.A.S designed the research; D.O., M.R, T.C., M.S.R., G.M. and F.A.S performed research; D.O, T.C. and F.A.S analyzed the data; M.S.R and G.M. contributed with analytical tools. The authors read and approved the final manuscript.

\section{Funding}

The analysis, interpretation of data and the manuscript writing was partially funded by Fundación Teófilo Hernando, a nonprofit foundation linked to Universidad Autónoma de Madrid.

\section{Availability of data and materials}

The dataset supporting the conclusions of this article is available under the petition to the corresponding author.

\section{Ethics approval and consent to participate}

The protocols complied with current Spanish legislation on clinical research in humans and were approved by the Research Ethics Committee from Hospital Universitario de La Princesa, duly authorized by the Spanish Drug Agency and under the guidelines of Good Clinical Practice. All participants gave their written informed consent for genotyping and were free to withdraw from the study at any time. The bioequivalence single-dose clinical trials were performed at Hospital Universitario de La Princesa (Madrid, Spain) between 2006 and 2010

\section{Consent for publication}

Not Applicable.

\section{Competing interests}

F.A.S. and D.O. have been consultants or investigators in clinical trials sponsored by the following pharmaceutical companies: Abbott, Alter, Chemo, Cinfa, FAES, Farmalíder, Ferrer, GlaxoSmithKline, Galenicum, Gilead, Italfarmaco, Janssen-Cilag, Kern, Normon, Novartis, Servier, Silverpharma, Teva and Zambon. The remaining authors declare no competing interests.

\section{Author details}

${ }^{1}$ Clinical Pharmacology Department, Hospital Universitario de La Princesa, Instituto Teófilo Hernando, Universidad Autónoma de Madrid (UAM), Instituto de Investigación Sanitaria La Princesa (IP), C/Diego de León 62, 28006 Madrid, Spain. ${ }^{2}$ UICEC Hospital Universitario de La Princesa, Plataforma SCReN (Spanish Clinical Reseach Network), Instituto de Investigación Sanitaria La Princesa (IP), Madrid, Spain. ${ }^{3}$ Research Unit, Fundación Burgos por la Investigación de la Salud, Hospital Universitario de Burgos, Burgos, Spain. ${ }^{4}$ Pharmacology Department, Facultad de Medicina, Universidad Autónoma de Madrid, Madrid, Spain.

Received: 3 February 2020 Accepted: 16 July 2020

Published online: 25 July 2020

\section{References}

1. Graham DY. Helicobacter pylori update: gastric cancer, reliable therapy, and possible benefits. Gastroenterology. 2015;148:719-31.

2. Hatlebakk JG, Katz PO, Castell DO. Medical therapy: management of the refractory patients. Gastroenterol Clin North Am. 1999;28:847-60.

3. Pan WJ, Goldwater DR, Zhang Y, Pilmer BL, Hunt RH. Lack of a pharmacokinetic interaction between lansoprazole or pantoprazole and theophylline. Aliment Pharmacol Ther. 2000;14:345-52.

4. Rhim SY, Park JH, Park YS, Lee MH, Hwang KG, Kim YS, et al. Pharmacokinetics and bioequivalence of $20 \mathrm{mg}$ omeprazole capsule in 24 healthy Korean male volunteers. Int J Clin Pharmacol Ther. 2009;47:23-9.

5. Román M, Ochoa D, Sánchez-Rojas SD, Talegón M, Prieto-Pérez R, Rivas Á, et al. Evaluation of the relationship between polymorphisms in CYP2C19 and the pharmacokinetics of omeprazole, pantoprazole and rabeprazole. Pharmacogenomics. 2014;15:1893-901.

6. Tytgat GN. Shortcomings of the first-generation proton pump inhibitors. Eur J Gastroenterol Hepatol. 2001;13(Suppl 1):S29-33.

7. AEMPS. Full prescribing information for omeprazole. Available at: http:// www.aemps.gob.es/cima/pdfs/es/ft/65687/FT_65687.pdf. Accessed 6 July 2020.
8. FDA full prescribing information for rabeprazole: http://www.fda.gov/ downloads/AdvisoryCommittees/CommitteesMeetingMaterials/ PediatricAdvisoryCommittee/UCM214745.pdf. Accessed 6 July 2020.

9. FDA. Omeprazole label. Available at: http://www.accessdata.fda.gov/ drugsatfda_docs/label/2012/019810s096lbl.pdf. Accessed 6 July 2020.

10. FDA full prescribing information for pantoprazole: http://www.accessdata. fda.gov/drugsatfda_docs/label/2012/020987s045lbl.pdf. Accessed 6 July 2020.

11. EMA (European Medicines Agency). Committee for Human Medicinal Products (CHMP). CHMP efficacy working party therapeutic subgroup on pharmacokinetics (EWP-PK). Questions \& Answers: Positions on specific questions addressed to the EWP therapeutic subgroup on Pharmacokinetics. 2010. Doc. Ref.: EMA/618604/2008 Rev. 2.

12. FDA (Food and Drugs Administration). US Department of Health and Human Services. Center for Drug Evaluation and Research (CDER). Foodeffect bioavailability and fed bioequivalence studies. Rockville: Guidance for Industry; 2002.

13. Sostek MB, Chen Y, Andersson T. Effect of timing of dosing in relation to food intake on the pharmacokinetics of esomeprazole. Br J Clin Pharmacol. 2007;64:386-90.

14. Thomson $A B$, Cohen P, Ficheux $H$, Fiorentini $P$, Domagala F, Homerin $M$, et al. Comparison of the effects of fasting morning, fasting evening and fed bedtime administration of tenatoprazole on intragastric $\mathrm{pH}$ in healthy volunteers: a randomized three-way crossover study. Aliment Pharmacol Ther. 2006;23:1179-87.

15. Yasuda S, Ohnishi A, Ogawa T, Tomono Y, Hasegawa J, Nakai H, et al. Pharmacokinetic properties of E3810, a new proton pump inhibitor, in healthy male volunteers. Int I Clin Pharmacol Ther. 1994;32:466-73.

16. Sachs $G$, Shin JM, Hunt R. Novel approaches to inhibition of gastric acid secretion. Curr Gastroenterol Rep. 2010;12:437-47.

17. Barrison AF, Jarboe LA, Weinberg BM, Nimmagadda K, Sullivan LM, Wolfe MM. Patterns of proton pump inhibitor use in clinical practice. Am J Med. 2001;111:469-73.

18. Lind T, Cederberg C, Ekenved G, Haglund U, Olbe L. Effect of omeprazole a gastric proton pump inhibitor - on pentagastrin stimulated acid secretion in man. Gut. 1983;24:270-6.

19. Mayer EA. The physiology of gastric storage and emptying. In: Johnson $L R$, Alpers DH, Jacobson ED, Christensen J, Walsh JH, editors. Physiology of the gastrointestinal tract. 3rd ed. New York: Raven Press; 1994. p. 929-76.

20. Benet LZ, Kroetz DL, Sheiner LB. Pharmacokinetics. The dynamics of drug absorption, distribution, and elimination. In: Hardman JG, Limbird LE, Molinoff PB, Ruddon RW, Gilman AG, editors. Goodman and Gilman's: the pharmacological basis of therapeutics. 9th ed. New York: McGraw-Hill; 1996. p. 3-28.

21. Liu Z, Ding L, Zhong S, Cao X, Jiang L, Duan H. Pharmacokinetics of a new immediate-release compound omeprazole capsule and its comparison with the enteric-coated formulation under fasting and fed conditions. Drug Res (Stuttg). 2013;63:370-5.

22. Ishizaki T, Horai Y. Review article: cytochrome P450 and the metabolism of proton pump inhibitors--emphasis on rabeprazole. Aliment Pharmacol Ther. 1999;13(Suppl 3):27-36.

23. Andersson T, Röhss K, Bredberg E, Hassan-Alin M. Pharmacokinetics and pharmacodynamics of esomeprazole, the S-isomer of omeprazole. Aliment Pharmacol Ther. 2001;15:1563-9.

24. Junghard O, Hassan-Alin M, Hasselgren G. The effect of the area under the plasma concentration vs time curve and the maximum plasma concentration of esomeprazole on intragastric pH. Eur J Clin Pharmacol. 2002;58:453-8.

25. Iwata A, Ikeda K, Hirose K, Takatori H, Takahashi K, Sanayama Y, et al. Predinner administration increases the efficacy of proton pump inhibitors on refractory GERD symptoms in connective tissue disease patients. Mod Rheumatol. 2013;23:357-64.

26. Swan SK, Hoyumpa AM, Merritt GJ. Review article: the pharmacokinetics of rabeprazole in health and disease. Aliment Pharmacol Ther. 1999;13(Suppl 3):11-7.

27. Huber R, Hartmann M, Bliesath H, Lühmann R, Steinijans WW, Zech K. Pharmacokinetics of pantoprazole in man. Int J Clin Pharmacol Ther. 1996; 34:185-94.

\section{Publisher's Note}

Springer Nature remains neutral with regard to jurisdictional claims in published maps and institutional affiliations. 